ISSN : ISSN 2442-4986

An-Nadaa: Jurnal Kesehatan Masyarakat, 7 (2) Desember 2020 : 132-138 https://ojs.uniska-bjm.ac.id/index.php/ANN/article/view/3922

\title{
HUBUNGAN PENDIDIKANDAN PERCEIVED BENEFIT DENGAN KEPESERTAAN JAMINAN KESEHATAN NASIONAL SEBAGAI PESERTA PBPU (MANDIRI) PADA MASYARAKAT DI KABUPATEN BANJAR
}

\author{
RELATIONSHIP OF EDUCATION AND PERCEIVED BENEFIT WITH THE \\ PARTICIPATION OF NATIONAL HEALTH ASSURANCE AS PBPU PARTICIPANTS \\ (INDEPENDENTS) IN COMMUNITY IN BANJAR DISTRICT
}

\author{
Asrinawaty ${ }^{1^{*}}$ Ahmad Zacky Anwary ${ }^{2}$, Yupisa Darma ${ }^{3}$ \\ 1,2,3 Fakultas Kesehatan Masyarakat, Universitas Islam Kalimantan (UNISKA) MAB \\ Banjarmasin \\ Jl. Adhyaksa. No.2. Kota Banjarmasin, Kalimantan Selatan. Indonesia \\ *Email: rienfkm@gmail.com
}

\begin{abstract}
South Kalimantan province according to data from the BPJS Kesehatan Banjarmasin Branch Office, the number of participants in the regency of the working area of this branch office includes Banjar district 218,746 (40.46\%), Banjarbaru City 152,837 (69.45\%), Kotabaru Regency 142,870 (44, 94\%), Kabupaten Tanah Bumbu 150,684 (48.71\%), Tanah Laut District 163,212 (47.88\%), Barito Kuala Regency 136,241 (44.12\%) and Banjarmasin City 471,027 (73.02\%). The district with the lowest UHC achievement was the Banjar Regency. The purpose of this study was to determine the relationship between education and perceived benefits with the participation of the National Health Insurance as PBPU (independent) in the community of Banjar Regency. Quantitative research method with analytic observational design through cross sectional approach. The population in this study were all family heads who live and reside in Banjar Regency. The sample used a formula according to Stanley Lemezhow with cluster techniques divided into 2 types of urban and rural sub-districts with a total sample of 196. The results showed that there was a significant relationship between education and perceived benefits and JKN membership independently $(p=0.000)$. The conclusion is that there is a relationship between education and perceived benefits with independent national health insurance participation in the community in Banjar Regency.
\end{abstract}

Keywords: Education; Perceifed Benefit; JKN Membership

\begin{abstract}
ABSTRAK
Provinsi kalimantan selatan menurut data dari Kantor Cabang BPJS kesehatan Banjarmasin, jumlah kepesertaan di kabupaten kabupaten wilayah kerja kantor cabang ini antara lain kabupaten Banjar 218.746 (40,46\%), Kota Banjarbaru 152.837 (69,45\%), Kabupaten Kotabaru 142.870 (44,94\%), Kabupaten tanah bumbu 150.684 (48,71\%), Kabupaten tanah laut 163.212 (47,88\%), Kabupaten barito kuala 136.241 (44,12\%) dan Kota Banjarmasin 471.027 (73,02\%). Kabupaten yang paling rendah capaian UHC nya adalah Kabupaten banjar. Tujuan penelitian ini adalah mengetahui hubungan pendidikan dan Perceived Benefit dengan kepesertaan Jaminan Kesehatan Nasional sebagai PBPU (mandiri) pada masyarakat Kabupaten Banjar. Metode penelitian kuantitatif dengan rancangan observasional analitik melalui pendekatan cross sectional. populasi dalam penelitian ini adalah seluruh kepala keluarga yang tinggal dan menetap di Kabupaten Banjar. Sampel menggunakan rumus menurut Stanley Lemezhow dengan teknik cluster yang dibagi menjadi 2 tipe kecamatan perkotaan dan pedesaan dengan total sampel 196. Hasil penelitian didapatkan hasil bahwa ada hubungan yang signifikan antara pendidikan dan perceived benefits dengan kepesertaan JKN secara mandiri $(\mathrm{p}=0,000)$. Kesimpulannya ada hubungan pendidikan dan perceived benefit dengan kepesertaan jaminan kesehatan nasional secara mandiri pada masyarakat di Kabupaten Banjar.
\end{abstract}

Kata Kunci : Pendidikan; Perceifed Benefit; Kepesertaan JKN 


\section{PENDAHULUAN}

Setiap orang berhak atas jaminan sosial dan berhak akan terlaksananya hak-hak ekonomi, sosial dan budaya sebagaimana tercantum dalam Deklarasi Perserikatan Bangsa-Bangsa tentang Hak Asasi Manusia pada tanggal 10 Desember 1948. Pada pasal 25 ayat (1) menyatakan, setiap orang berhak atas tingkat hidup yang memadai untuk kesehatan dan kesejahteraan dirinya dan keluarganya, termasuk atas hak pangan, pakaian, perumahan dan perawatan kesehatan serta pelayanan sosial yang diperlukan, dan berhak atas jaminan pada saat menganggur, menderita sakit, cacat, menjadi janda/duda, mencapai usia lanjut atau keadaan lainnya yang mengakibatkannya kekurangan nafkah, yang berada di luar kekuasaannya (1).

Jaminan kesehatan nasional (JKN) adalah perintah Undang-Undang Dasar dan UndangUndang Sistem Jaminan Sosial Nasional (SJSN) serta merupakan praktik negara beradab di seluruh dunia. Tahun 2005 Organisasi Kesehatan Dunia (WHO) mendesak semua negara anggota menjamin seluruh penduduknya. Dalam mekanismenya pasar telah gagal dalam mencapai kesetimbangan harga, pasokan, dan kualitas layanan kesehatan, porsi terbesar sumber pendanaan kesehatan di seluruh dunia berasal dari dana publik. Dana privat hanya sebagai pelengkap. Sumber dana publik berasal dari pajak dan atau iuran jaminan sosial. Negara negara tetangga asia lain seperti filipina, thailand, malaysia, srilanka telah lebih dulu menjalankan skema JKN dinegaranya yakni ada pembayar tunggal yang telah diatur dalam perundang undangan masing masing negara (2)

JKN merupakan program jaminan sosial untuk setiap orang, (sesuai amanat UUD 1945 pasal 34) juga pasal $28 \mathrm{H}$ negara memenuhi hak layanan kesehatan. Diharapkan sampai dengan tahun 2019 semua masyarakat Indonesia sudah Universal Health Coverage, apalagi JKN telah memenuhi prinsip syariah, karena wajib (menghindari anti seleksi), dari dana hibah peserta, tolong menolong (taawunuu) dan saling mencukupi (takaful) dengan investasi sejalan dengan pertumbuhan perbankan dan investasi deposito atau sukuk syariah (3).

Berdasarkan data BPJS Kesehatan sampai dengan tanggal 1 november 2017 jumlah peserta yang terdaftar dalam program JKN yang dikelola oleh BPJS Kesehatan berjumlah 183.579.086 jiwa.
Kepesertan di dalam program JKN ini terbagi menjadi beberapa segmen atau jenis kepesertaan dengan jumlah peserta PBI APBN 92.211.726, PBI APBD 19.381.926, PPU PNS 13.719.929, PPU TNI 1.570.636, PPU POLRI 1.241.706, PPU BUMN 1.420.297, PPU BUMD 172.890, PPU Swasta 24.853.778, PBPU 24.041.754, dan Bukan Pekerja (BP) 4.964.442 jiwa. Pekerja Bukan penerima Upah (PBPU) atau yang lebih akrab dengan sebutan peserta mandiri / Umum, hingga tanggal 1 november 2017 telah berjumlah 24.041.754 disandingkan dengan jumlah kepesertaan seutuhnya angka tersebut hanya berjumlah 13,10\% dari jumlah kepesertaan yang ada dalam program ini. Seluruh penduduk Indonesia sebagaimana diatur dalam undang undang yang telah diamanatkan kepada BPJS kesehatan ini seharusnya pada tahun 2019 sudah menjadi peserta JKN agar tercipta Universal Health Coverage (UHC). Mengingat hanya tinggal 1 tahun tersisa menuju UHC di indonesia angka 13,10 \% bagi peserta mandiri ini adalah angka yang bisa dikatakan kecil dibandingkan jumlah penduduk yang masih belum terdaftar di dalam program JKN ini (4).

Di Provinsi Kalimantan Selatan menurut data dari Kantor Cabang BPJS kesehatan Banjarmasin, jumlah kepesertaan di kabupaten kabupaten wilayah kerja kantor cabang ini antara lain kabupaten Banjar 218.746 (40,46\%), Kota Banjarbaru 152.837 (69,45\%), Kabupaten Kotabaru 142.870 (44,94\%), Kabupaten tanah bumbu $150.684(48,71 \%)$, Kabupaten tanah laut $163.212(47,88 \%)$, Kabupaten barito kuala 136.241 $(44,12 \%)$ dan Kota Banjarmasin 471.027 (73,02\%). Dua kabupaten yang paling rendah capaian UHC nya adalah Kabupaten banjar dan batola. Untuk kabupaten banjar sendiri apabila dilihat dari segi persentase memang kecil karena data pembandingnya adalah jumlah penduduk dikabupaten Banjar. Namun apabila dilihat dari segi jumlah nya sudah lumayan, bisa mencapai angka 218.746 jiwa, dan peserta mandiri nya sebanyak 60.297, ini berarti hanya sekitar 11,15\% warga kabupaten Banjar yang telah terdaftar sebagai peserta mandiri (PBPU) (4).

Sejalan dengan Teori HBM dikemukakan pertama kali oleh Rosenstock 1966, kemudian disempurnakan oleh Backer, dkk pada tahun 1970 dan 1980.HBM memperkirakan perilaku sebagai hasil keyakinan atau kepercayaan yang merupakan persepsi individu terhadap kerentanan yang 
dirasakan terhadap suatu penyakit (Perceived susceptibility), keseriusan yang dirasakan (Perceived seriousness), manfaat yang diterima(Perceived benefits) dan rintangan yang dialami(Perceived barrier) dalam melawan penyakitnya,Tindakan ini akan tergantung pada manfaat yang dirasakan dan rintangan yang ditemukan dalam mengambil tindakan tersebut namun pada umumnya manfaat tindakan lebih menentukan daripada rintangan-rintangan yang mungkin ditemukan di dalam melakukan tindakan tersebut, dan hala-hal yang memotivasi tindakan tersebut(cues to action) berasal dari informasi dari luar atau nasehat mengenai permasalahan kesehatan (5).

Ditunjang dari hasil penelitian penelitian sebelumnya didaerah lain menyatakan bahwa Sebagian besar responden non peserta JKN menyatakan tidak mengikuti program JKN karena tidak mengetahui manfaat yang akan mereka peroleh dari program tersebut. Persepsi responden terhadap manfaat JKN adalah satu-satunya variabel yang berhubungan dengan kepesertaan JKN. Variabel yang tidak terbukti berhubungan dengan kepesertaan JKN secara mandiri yaitu umur, pendidikan, penghasilan, persepsi kerentanan, persepsi keparahan, persepsi ancaman, persepsi hambatan dan sosialisasi tentang JKN.

Berdasarkan data dan teori di atas, peneliti tertarik untuk meneliti mengenai hubungan Pendidikan dan persepsi manfaat (Perceived Benefits) dengan kepesertaan Jaminan Kesehatan Nasional (JKN) sebagai peserta PBPU (mandiri) pada masyarakat di Kabupaten Banjar.

\section{BAHAN DAN METODE}

Penelitian ini menggunakan rancangan penelitian observasional analitik yang bertujuan untuk menganalisis hubungan antara pendidikan dan perceived benefit dengan kepesertaan Jaminan Kesehatan Nasional (JKN) secara mandiri pada masyarakat Kabupaten Banjar. Adapun desain penelitian yang digunakan adalah dengan pendekatan cross sectional, yaitu untuk menganalisis hubungan suatu akibat dan variabel atau karakteristik yang terdapat dimasyarakat pada suatu waktu tertentu. Populasi dalam penelitian ini yaitu masyarakat yang menjadi Peserta mandiri dan bukan peserta JKN umur $\geq 18$ tahun, Kepala keluarga baik laki-laki maupun perempuan dan masyarakat yang sudah memiliki pekerjaan. Apabila seseorang ingin meneliti semua elemen yang ada dalam wilayah penelitian, maka penelitiannya merupakan penelitian populasi (6). Pengumpulan data dalam penelitian ini dengan melakukan wawancara mengggunakan kuesioner. Instrumen yang digunakan adalah lembar kuesioner. Variabel terikat dalam penelitian adalah Pemanfaatan Layanan BPJS Kesehatan. Sedangkan variabel bebas adalah Pendidikan dan persepsi manfaat (Perceived Benefits. Analisis data menggunakan data primer berupa data deskritif akan disajikan dalam bentuk tabel dan narasi. Kemudian data dianalisis yakni menggunakan Uji Chi Square. Nilai derajat kemaknaan adalah apaabila $\mathrm{p}$ value $<0,05$ maka hipotesis nol akan ditolak. Analisis data akan menggunakan program SPSS (Statistical Package For Social Science).

\section{HASIL DAN PEMBAHASAN}

\section{Hasil Penelitian}

\section{Analisis Univariat}

Tabel 1. Distribusi frekuensi Kepesertaan JKN dan tingkat pendidikan sebagai PBPU (Mandiri) Pada Masyarakat Di Kabupaten Banjar

\begin{tabular}{lrc}
\hline \multicolumn{1}{c}{ Variabel } & n & \% \\
\hline Kepesertaan JKN PBPU & & \\
Terdaftar Peserta JKN & 95 & 48,5 \\
Belum Terdaftar Peserta JKN & 101 & 51,5 \\
Tingkat Pendidikan & & \\
Tinggi (Sarjana/Diploma) & 70 & 35,7 \\
Menengah & 80 & 40,8 \\
(SMA/SMK/MAN) & & \\
Dasar (SD/SMP) & 46 & 23,5 \\
Perceifed benefits & & \\
Tinggi & 41 & 20,9 \\
Rendah & 155 & 79,1 \\
Total & 196 & 100,0 \\
\hline
\end{tabular}

Berdasarkan tabel 1, pada variabel kepesertaan JKN PBPU, dapat diketahui, 101 responden $(51,5 \%)$ belum terdaftar sebagai peserta JKN dan 95 responden $(48,5 \%)$ yang terdaftar sebagai peserta JKN secara mandiri. Sedangkan untuk variabel tingkat pendidikan, didapatkan hasil penelitian terhadap sampel yang dilakukan di kantor Kabupaten Banjar, responden yang mempunyai 
tingkat pendidikan Menengah (SMA/SMK/MAN) paling banyak yakni sebanyak $80(40,8 \%)$ responden, responden yang berpendidikan tinggi (sarjana/Diploma) sebanyak $70 \quad(35,7 \%)$ serta responden yang tingkat pendidikan dasar (SD/SMP) sebanyak 46 (23,5 \%). Hal ini mengisyaratkan bahwa tingkat pendidikan yang rendah berbanding lurus terhadap tingkat kepesertaan JKN sebagai PBPU mandiri pada masyarakat Kabupaten Banjar.

Sedangakn pada variabel perceifed benefit, menunjukkan bahwa persentase tertinggi adalah responden yang memiliki persepsi rendah akan manfaat JKN yaitu 155 responden (79,1\%) sedangkan yang memiliki persepsi tinggi akan manfaat JKN adalah sebanyak 41 responden (20,9\%). Tingginya persentase responden yang memiliki persepsi rendah akan manfaat JKN yaitu 79, 1\% disebabkan masih banyaknya responden yang kurang memahami akan manfaat yang ditawarkan BPJS kesehatan dalam program JKN ini. Hal ini dapat tercermin ketika responden mengisi kuesioner, pada pernyataan 1 dan 2, yaitu Menjadi atau mendaftar sebagai peserta JKN Dapat mencegah masalah kesehatan di kemudian hari responden menjawab tidak setuju sebanyak 144 responden, Sebagai peserta JKN kita Tidak Dapat mengatasi biaya pengobatan saat memerlukan biaya besar ini merupakan pernyataan negatif dan responden menjawab setuju sebanyak 141 responden. Hal ini mengindikasikan seperti adanya logika terbalik, padahal program JKN ini tujuan dan manfaat nya secara umum sudah tergambar dengan dua pernyataan ini, namun masayarakat kebanyakannya belum memahami betul apa manfaat dari ikut program JKN ini. Responden yang memiliki persepsi tinggi akan manfaat JKN adalah 41 (20,9\%), dilihat dari hasil kuesioner responden mengetahui dan memahami akan manfaat yang ditawarkan BPJS kesehatan dalam program JKN sehingga menjawab sangat setuju dan setuju pada pertanyaan positif dan menjawab sangat tidak setuju dan tidak setuju pada pertanyaan negatif yang diberikan. Responden juga menjawab ragu-ragu pada pertanyaan negatif yang mereka kurang pahami sehingga skor hasil perhitungan skala persepsi mereka tinggi.

\section{Analisis Bivariat}

Tabel 2 Hubungan pendidikan dan perceifed Benefit dengan Kepesertaan JKN Pada Masyarakat Di Kabupaten Banjar

\begin{tabular}{lccccccc}
\hline \multirow{2}{*}{ Variabel } & \multicolumn{9}{c}{ Kepesertaan JKN } & Total & $\%$ & P Value \\
\cline { 2 - 4 } & \multicolumn{2}{c}{ Terdaftar } & \multicolumn{2}{c}{ Belum Terdaftar } & & & \\
Pendidikan & $\mathbf{n}$ & $\%$ & $\mathbf{n}$ & $\%$ & & & \\
Tinggi & 65 & 68,4 & 5 & 5,0 & 70 & 100 & 0,000 \\
Menengah & 24 & 25,3 & 56 & 55,4 & 89 & 100 & \\
Dasar & 6 & 6,3 & 40 & 39,6 & 46 & 100 & \\
Perceifed Benefit & & & & & & & \\
Tinggi & 32 & 33,7 & 9 & 8,9 & 41 & 100 & 0,000 \\
Rendah & 63 & 66,3 & 92 & 91,1 & 155 & 100 &
\end{tabular}

Berdasarkan tabel 2 dapat diketahui bahwa dari 196 responden, yang telah menjadi peserta JKN secara mandiri dengan kategori pendidikan tinggi terdapat $65(68.4 \%)$ responden dan dengan kategori pendidikan menengah $24(25.3 \%)$ responden serta kategori pendidikan dasar $6(6.3 \%)$ responden. Sedangkan yang Belum menjadi peserta JKN dengan kategori pendidikan tinggi adalah $5(5.0 \%)$ responden dan kategori pendidikan menengah yaitu 56 (55.4\%) responden serta kategori pendidikan dasar adalah $40(39.6 \%)$ responden. Melihat nilai Asymp. Sig, Jika nilai Asymp. Sig < 0,05, maka terdapat hubungan yang signifikan antara baris dengan kolom. Jika nilai Asymp. Sig $>0,05$, maka 
tidak terdapat hubungan yang signifikan antara baris dengan kolom. Sehingga, diperoleh kesimpulan bahwa Terdapat Hubungan Signifikan pendidikan Dengan Kepesertaan Jaminan Kesehatan Nasional Sebagai Peserta PBPU (mandiri) Pada Masyarakat di Kabupaten Banjar dengan nilai ( $p=v a l u e) \quad 0,000<$ 0,05 .

Responden yang memiliki penilaian terhadap manfaat atau perceifed benefit terkategori tinggi sebanyak 32 (33.7\%) responden telah terdaftar sebagai peserta JKN sebagai PBPU (mandiri) sedangkan yang belum sebanyak 9 (8.9\%) responden. Sedangkan yang memiliki penilaian dengan kategori rendah terdapat $63(66.3 \%)$ yang belum menjadi peserta JKN sebagai PBPU (mandiri). Dalam pengambilan keputusan ini berpedoman pada dua hal, yakni membandingkan nilai Asmp. Sig dengan batas kritis yakni 0,05.Melihat nilai Asymp. Sig. Jika nilai Asymp. Sig < 0,05, maka terdapat hubungan yang signifikan antara baris dengan kolom. Sedangkan Jika nilai Asymp. Sig > 0,05, maka terdapat hubungan yang signifikan antara baris dengan kolom. Sehingga, diperoleh kesimpulan bahwa Terdapat Hubungan Signifikan Perceived Benefit Dengan Kepesertaan Jaminan Kesehatan Nasional Sebagai Peserta PBPU (mandiri) Pada Masyarakat di Kabupaten Banjar dengan nilai Sig. ( $p=$ value $) 0,000<0,05$.

\section{PEMBAHASAN}

\section{Kepesertaan JKN sebagai PBPU (mandiri)}

Berdasarkan tabel 1 dapat diketahui, 101 responden $(51,5 \%)$ belum terdaftar sebagai peserta JKN dan 95 responden (48,5\%) yang terdaftar sebagai peserta JKN secara mandiri. Data kepesertaan kantor BPJS kesehatan cabang banjarmasin Kabupaten Banjar adalah 62.466 jiwa (11, 45\%) dari 543799 jiwa penduduk Kabupaten Banjar. Hal ini membuktikan bahwa kepesertaan mandiri di Kabupaten Banjar memang masih rendah dan harus ditingkatkan untuk dapat mencapai target UHC.

Setelah dilakukan penelitian di daerah kabupaten banjar, Selain dua variabel yang diambil dalam penelitian ini, banyak faktor lainnya yang ikut andil besar saat peserta mengambil keputusan untuk mendaftarkan diri beserta keluarga ke dalam program JKN ini atau tidak. Faktor yang paling mempengaruhi kepsertaan sebagai peserta PBPU (mandiri) ini adalah keadaan ekonomi didalam keluarga tersebut, karena pendaftaran PBPU mandiri ini harus sekeluarga maka bagi mereka mereka yang didalam 1 kartu keluarga memiliki jumlah anggota keluarga banyak anak maka akan berpikir berkali kali apakah daftar atau tidak, yang membuat mereka ujung ujungnya hanya mendaftar ketika akan menjalani suatu tindakan medis yang berbiaya mahal, dan tidak bayar lagi ketika sudah sembuh. Ini merupakan fenomena yang lazim terjadi di masyarakat, kabupaten banjar tentunya (7).

\section{Pendidikan}

. Semakin tinggi pendidikan jelas akan mempengaruhi pribadi seseorang dalam berpendapat, berfikir, bersikap dalam mengambil keputusan juga tindakan, termasuk dalam merencanakan kesehatan keluarganya salah satunya yaitu dengan mengikuti program JKN. Seseorang yang berpendidikan tinggi akan cenderung meningkatkan kesadarannya pada kesehatan serta konsekuensinya. Orang yang berpendidikan tinggi memiliki pola pikir dan persepsi yang lebih baik dibandingkan yang berpendidikan rendah. Orang yang berpendidikan tinggi sadar bahwa hidup itu penuh dengan ketidakpastian sehingga seseorang yang berpendidikan tinggi cenderung memiliki asuransi dalam hal ini adalah dalam bentuk jaminan kesehatan nasional, selain jaminan kesehatan nasional memiliki tingkat atau taraf iuran yang sangat jauh signifikan dibanding dengan jaminan kesehatan (asuransi) swasta namun manfaat yang diberikan jauh sangat berbeda. Ketika asuransi sudah dipastikan akan menolak klaim terhadap penyakit yang pasti akan terjadi namun berbeda dengan BPJS kesehatan yang tetap menjamin manfaat tersebut, sehingga masayarakat dengan pola pikir pendidikan nya lebih tinggi sudah pasti menyadari hal ini sehingga mempengaruhi keikutsertaannya dalam program jaminan kesehatan yang diselenggarakan oleh BPJS kesehatan ini. Tingkat pendidikan mempengaruhi kesadaran individu melakukan tindakan perencanaan dan pengendalian untuk memahami risiko atas kesehatan dirinya. Dikatakan bahwa semakin tinggi tingkat pendidikan, maka semakin bertambah pengetahuan dan semakin bertambah pula kebutuhan akan pelayanan kesehatan. Hal ini akan meningkatkan keinginan untuk menjadi peserta jaminan kesehatan terlebih dalam skema JKN yang diselenggarakan oleh BPJS kesehatan (8). 


\section{Perceifed Benefits}

Berdasarkan sebaran data pada tabel perceifed benefits dengan kepesertaan JKN diketahui bahwa penilaian yang membentuk persepsi seseorang dalam hal ini mempengaruhi secara langsung keikutsertaan program JKN secara mandiri, ini dibuktikan dengan terdapatnya 32 dari 41 responden yang memiliki persepsi tinggi lebih cenderung untuk ikut program JKN secara mandiri, hal ini disebabkan mereka telah memiliki persepsi atau penilaian yang terkategorikan tinggi akan manfaat-manfaat yang diberikan oleh program JKN yang diselenggarakaan oleh BPJS kesehatan.

Dari tabel tersebut juga tergambarkan bahwa 92 dari 155 responden yang memiliki penilaian terdahap perceifed benefit yang terkategorikan rendah memilih untuk tidak atau setidaknya masih belum mendaftarkan diri untuk ikut serta dalam program JKN sebagai PBPU ini. Ketika digali jauh lebih dalam selain faktor utama yakni perceifed benefit dari 92 orang yang belum terdaftar itu juga memiliki alasan lain nya baik itu ekonomi maupun karena ketidak tahuannya. Sedangkan untuk yang memiliki penilaian yang rendah namun sudah terdaftar, kalau diperhatikan di dalam tabel tersebut ada 63 dari 155 responden, mereka ini pun memiliki persepsi yang rendah terhadap manfaat yang didapat dengan ikut JKN ini, namun nyatanya mereka tetap mendaftar, hal ini yang membuat peneliti bertanya lebih dalam. Mereka mendaftar dengan alasan karena memang bukan karena ingin merasakan manfaat secara medis, namun karena memang tuntutan kewajiban undang undang seperti yang dituangan dalam PP no 86 tahun 2013 sanksi sanksi apa saja ketika penduduk tidak segera mendaftarkan diri dan keluarganya. Sebagai contoh mahasiswa yang ingin melakukan daftar ulang di salah satu universitas negeri di kalimantan selatan diwajibkan agar memiliki kartu identitas sebagai peserta JKN, jadi para orang tua yang anaknya kuliah di universitas itu, yang bukan PNS tentunya maka akan mendaftar JKN ini tanpa melihat adanya benefit medis (9).

Hal ini kemungkinan dikarenakan perceived benefits hanya merupakan sebagian kecil dari berbagai macam persepsi yang mempengaruhi seseorang. Menurut teori Health Belief Model, persepsi yang mungkin saja mempengaruhi selain perceived benefits adalah persepsi kemungkinan, persepsi keseriusan, persepsi ancaman dan cues to
action.Hal yang mempengaruhi perilaku, yaitu kepercayaan, kebiasaan, nilai-nilai, faktor sosiodemografi, lingkungan fisik dan sarana. Kebiasaan hanya mungkin dikembangkan melalui pengorbanan yang disertai pelatihan dan pengulangan serta konsisten. Demikian sulitnya membangun kebiasaan positif, karena setiap kebiasaan harus didukung oleh pemahaman tentang perbuatan dan mampu mengetahui keuntungan dari perilaku tersebut (10).

\section{KESIMPULAN DAN SARAN}

Berdasarkan hasil penelitian, didapatkan simpulan bahwa pada Variabel Pendidikan terhadap Kepesertan JKN PBPU (mandiri) didapatkan nilai Sig. ( $\mathrm{p}=$ value) $0,000<0,05$. Ada hubungan pendidikan dengan kepesertaan JKN sebagai peserta PBPU ( mandiri) pada masyarakat Kabupaten Banjar (P-Value 0,000). Variabel Perceifed Benefits terhadap Kepesertan JKN PBPU (mandiri) didapatkan nilai Sig. ( $\mathrm{p}=$ value) $.0,000<0,05$ dan ada hubungan perceived benefits dengan kepesertaan JKN kepesertaan JKN sebagai peserta PBPU ( mandiri ) pada masyarakat Kabupaten Banjar (P-Value). Saran dalam penelitian ini adalah bagi BPJS Kesehatan Kabupaten Banjar dapat dijadikan sebagai bahan perencanaan, pelaksanaan, monitoring serta evaluasi untuk meningkatkan kepesertaan masyarakat Kabupaten Banjar, terutama dalam segmentasi peserta PBPU (mandiri). Banyak hal yang dapat dilakukan diantaranya dengan meningkatkan sosialisasi dan pro mosi terkait manfaat JKN secara langsung terutama di kecamatan tipe pedesaan yang masih minim informasi terkait program JKN agar masyarakat memahami keuntungan apa saja yang mereka dapatkan jika mengikuti program JKN, sehingga target tahun berikutnya dapat tercapai dan bagi peneliti selanjut nya yang ingin melakukan penelitian di wilayah kabupaten banjar, maupun yang ingin melakukan penelitian dengan judul terkait kepesertaan jaminan kesehatan nasional, sangat disarankan untuk mengambil jumlah variabel bebas yang lebih bervariasi, selain itu juga sangat disarankan untuk mengambil judul dengan keterkaitannya kepesertaan dan kepatuhan peserta dalam melakukan hak dan kewajiban sebagai peserta jaminan kesehatan nasional. 


\section{DAFTAR PUSTAKA}

1. Nahilma Mona. 2016 Hubungan antara umur, pendidikan, pengetahuan dan pendapatan dengan kepesertaan jaminan kesehatan nasional secara mandiri di Kabupaten HSS. Skripsi. Banjarbaru: Universitas Lambung Mangkurat.

2. Nancy I.S. 2014. Hubungan karakteristik dan persepsi masyarakat tentang jaminan kesehatan nasional (JKN) terhadap keikutsertaan menjadi peserta JKN di Kota Medan. Skripsi, Medan: Universitas Sumatra Utara.

3. Putri IA. 2015. Hubungan faktor sosiodemografi, persepsi dan sosialisasi dengan kepesertaan pasien rawat jalan dalam program jaminan kesehatan nasional secara mandiri di Puskesmas Denpasar Timur. Tesis. Denpasar: Universitas UDAYANA.

4. Badan Penyelenggaraan Jaminan Sosial. Laporan Tahunan Badan Penyelenggaraan Jaminan Sosial Kota. 2018. Banjarmasin.

5. Sastradimulya F, Nurhayati E, dan Susanti Y. 2015. Hubungan tingkat pengetahuan pasien tentang jaminan kesehatan nasional dengan status kepesertaan BPJS. Artikel penelitian.

6. Arikunto, S. 2006. Metode Penelitian Kualitatif. Jakarta: Bumi Aksara

7. Siswoyo BE, Prabandaryi YS, Hendrartini Y. 2015. Kesadaran pekerja sektor informal terhadap program jaminan kesehatan nasional di Provinsi Daerah Istimewa Yogyakarta. Jurnal Kebijakan Kesehatan Indonesia

8. Subari ED, Djuhaeni H, Wiwaha G. 2014. Analisis faktor-faktor yang memengaruhi intensi menjadi peserta mandiri jaminan kesehatan. Artikel penelitian.

9. Widhiastuti I. 2015. Hubungan faktor sosiodemografi, persepsi dan sosialisasi dengan kepesertaan pasien rawat jalan dalam program jaminan kesehatan nasional secara mandiri. Tesis. Denpasar: Universitas Udayana Denpasar.

10. Yulianto S. 2008. Hubungan tingkat pendidikan dan pendapatan keluarga dengan pemanfaatan kepesertaan askeskin di Puskesmas Nglipar II Gunungkidul. Tesis. Universitas Sebelas Maret. Surakarta. 